\title{
César M. Arconada en su exilio de Moscú : poesía, historia y
} política

Manuel Aznar soler

\section{Citer ce document / Cite this document :}

Aznar soler Manuel. César M. Arconada en su exilio de Moscú : poesía, historia y política. In: Exils et migrations ibériques au XXe siècle, $n^{\circ} 8,2000.60$ ans d'exil républicain : des poètes espagnols entre mémoire et oubli. Anthologie. pp. 49-70;

doi : https://doi.org/10.3406/emixx.2000.1042

https://www.persee.fr/doc/emixx_1245-2300_2000_num_2_8_1042

Fichier pdf généré le 28/08/2018 


\title{
César M. Arconada en su exilio de Moscú: poesía, historia y política
}

\author{
Presentación de Manuel Aznar Soler*
}

César Muñoz Arconada (Astudillo -Palencia- 1898-Moscú 1964), vinculado en sus inicios a las vanguardias literarias "deshumanizadas" de los años veinte, era ya un escritor prestigioso antes del 18 de julio de 1936. Redactor-jefe de la revista La Gaceta Literaria y colaborador de Octubre o Nueva Cultura entre otras ${ }^{1}$, crítico literario, ensayista, novelista, poeta y dramaturgo, fue uno de los primeros escritores españoles que se afilió al Partido Comunista de España ${ }^{2}$, un proceso que el propio escritor explicó con toda claridad en una breve "Autobiografía" que editó la revista Commune en abril de 1936 con motivo de la traducción a la lengua francesa de su novela Reparto de tierras ${ }^{3}$. Sed y Urbe, que mereció la atención crítica de Francisco Ayala ${ }^{4}$, son sus dos primeros libros poéticos, escritos y publicados en ese "paraíso de las musarañas" de la vanguardia "deshumanizada" del que habla en su "Autobiografía" y del que pronto se alejo. En efecto, ya militante comunista, Arconada va a protagonizar una ruptura radical con esa antigua

\footnotetext{
- Universitat Autònoma de Barcelona.

${ }^{1}$ Christopher H. Cobb ha anotado sus colaboraciones entre 1920 y 1938 en periódicos y revistas en su libro De Astudillo a Moscú. Obra periodística, Valladolid, Ámbito Ediciones, 1986, pp. 341-359.

${ }^{2}$ José Antonio Guerrero Villalba fecha "su militancia política desde el mes de marzo de 1931 en el PCE" ("La poesía de Arconada", AA. VV., Homenaje al profesor Antonio Gallego Morell, edición de C. Argente del Castillo, A. De la Granja, J. Martínez Marín y A. Sánchez Trigueros, Granada, Universidad de Granada, 1989, p. 113).

${ }^{3}$ César M. Arconada, “Autobiografía”, Nueva Cultura, Valencia, 11 (marzo-abril de 1936), p. 11.

${ }^{4}$ Francisco Ayala, "Urbe", La Gaceta Literaria, 39 (1 de agosto de 1928), apud Cristopher H. Cobb, op. cit., pp. 327-329.
} 
musa de las musarañas líricas y durante los años de la II República y antes de la guerra civil publicará dos nuevos libros poéticos, fecundados por su nueva musa revolucionaria: Nuevo Amor y Vivimos en una noche oscura, reseñado este último por José Díaz Fernández ${ }^{6}$ y al que el propio autor caracteriza como compuesto por "poemas dramáticos, atravesados de dolor y esperanza", que reflejan "el ambiente de angustia del mundo y de España". Durante la guerra civil, Arconada, miliciano que "está luchando heroicamente desde los primeros días de la sublevación fascista en los frentes del Norte, primero en Irún y ahora en Asturias ${ }^{8}$ ", fue colaborador de periódicos y revistas como Frente Rojo y Mundo Obrero y autor de numerosos romances, que reunió en un libro titulado Romances de la guerra, algunos de los cuales han sido reproducidos con posterioridad ${ }^{9}$.

Exiliado en la Unión Soviética a partir de $1939^{10}$, Arconada siguió escribiendo ocasionalmente poemas, aunque no llegó a editarlos en libro. Colaborador asiduo de la prensa vinculada al PCE, se editan aquí doce poemas: nueve "olvidados" entre las páginas de revistas como España Popular (seis), Nuestro Tiempo (dos) -aparecidas ambas en México- o en libros colectivos como el publicado en homenaje a Julián Grimau (uno); y tres inéditos, que se conservan entre los materiales del escritor en la sección de Manuscritos de la Biblioteca Nacional de Madrid, tal y como consta en la anotación correspondiente. Estos poemas de Arconada están determinados, ante todo, por la militancia comunista del autor y se refieren a hechos

${ }^{5}$ Rafael Cruz afirma que "Arconada publicó un libro de poemas en 1934, titulado Nuevo amor", en su libro El arte que inflama. La creación de una literatura política bolchevique en España, 1931-1936, Madrid, Biblioteca Nueva, 1999, p. 113, nota 93.

6 José Díaz Fernández, "Reparto de tierras y Vivimos en una noche oscura”, Política (31 de enero de 1936), apud Christopher H. Cobb, op. cit., pp. 329-331.

${ }^{7}$ César M. Arconada, “Autobiografía”, op. cit.

8.César M. Arconada", El Mono Azul, 8 (15 de octubre de 1936), p. 6.

${ }^{9}$ Gonzalo Santonja ha reproducido "sus tres romances (el libro contiene catorce) de tema específicamente asturiano", en su edición de La guerra en Asturias (crónicas y romances), op. cit., pp. 111-127.

10 Sobre el tema puede consultarse mi artículo "Teatro, literatura y cultura del exilio republicano español en la Unión Soviética (1939-1949)", publicado en la revista Exils et Migrations lbériques, 6 (1999), pp. 61-76, número monográfico titulado "60 ans d'exil républicain : des écrivains espagnols entre mémoire et oubli”, coordinado por M. Aznar Soler, Nigel Dennis y Bernard Sicot. 
históricos ("Barcelona", sobre la huelga de tranvías en 1951) o a héroes políticos "ejemplares" del comunismo internacional: "¡Vive Dolores!", dedicado a Dolores Ibárruri, "Pasionaria", o "Eternamente Stalin", "Y los pueblos de España...", dedicados ambos a Stalin con motivo de su muerte. Otros poemas se refieren a la lucha contra la dictadura franquista y exaltan la memoria de héroes de la resistencia popular, como los consagrados a la guerrillera Manuela Sánchez ("Pasó el tiempo..."), al mítico guerrillero gallego Manuel Ponte, que murió en combate en abril de 1947 ("Romance del niño bueno y el civilón patilargo") o a un camarada como Julián Grimau, asesinado por el franquismo ("Grimau, muerto inmortal"). En otros poemas, se apela a la resistencia del pueblo español contra el imperialismo yanqui ("Nuestra España" o el ya citado "Barcelona") y se insta a una nueva guerra de la independencia ("El alcalde Móstoles"), una actitud combatiente en la que la revolución china constituye el mejor ejemplo de victoriosa guerra de liberación ("Todo esto díselo tú"). Otros poemas, por fin, están dedicados a personalidades del exilio republicano español de 1939 como Antonio Machado, símbolo de la fusión entre el poeta y su pueblo ("Antonio Machado"), o a artistas también exiliados en la Unión Soviética como el escultor y camarada Alberto Sánchez, a quien le dedica un hermoso soneto ("A Alberto, en Moscú").

Estos doce poemas, olvidados o inéditos de Arconada, demuestran hasta qué punto la vinculación entre poesía, historia y política fue fecunda e intensa para la mayoría de poetas comunistas del exilio republicano español de 1939, no sólo para Arconada sino también, por ejemplo, para Rafael Alberti o Juan Rejano. Es cierto que la literatura de partido no tiene por qué ser intrínsecamente perversa, pero también es verdad que la mayoría de esta literatura militante, leída con la perspectiva histórica que nos confiere el presente, resulta más interesante como testimonio artístico de un tiempo y de una época -de unas convicciones éticas o de unas necesidades políticas-que por su propia calidad artística. En suma, estos doce poemas de Arconada vienen a demostrar que, salvo honrosas excepciones, la musa del poeta exiliado está cargada de buenas intenciones políticas pero, desgraciadamente, produce por lo general resultados estéticamente insatisfactorios. 


\section{BIBLIOGRAFIA}

Obra poética de César M. Arconada:

Sed, 1921.

Urbe, Málaga, Imprenta Sur, 1928.

Nuevo amor, Madrid, 1934.

Vivimos en una noche oscura, Madrid-París, Publicaciones Izquierda, 1936.

Romances de la guerra, Santander, Unidad, 1937.

Estudios sobre César M. Arconada:

ARConAda, César M., De Astudillo a Moscú. Obra periodística, edición de Christopher H. Cobb, Valladolid, Ámbito Ediciones, 1986.

AYAlA, Francisco, "Urbe”, La Gaceta Literaria, 39 (1 de agosto de 1928).

CRUZ, Rafael, "César Arconada. La literatura al servicio de una idea", El arte que inflama. La creación de una literatura política bolchevique en España, 1931-1936, Madrid, Biblioteca Nueva, 1999, pp. 101-116.

Guerrero Villalba, José Antonio, "La poesía de Arconada", AA. VV., Homenaje al profesor Antonio Gallego Morell, edición de C. Argente del Castillo, A. De la Granja, J. Martínez Marín y A. Sánchez Trigueros, Granada, Universidad de Granada, 1989, pp. 109-117.

LECHNER, Jan, El compromiso en la poesía española del siglo XX. Parte primera: de la generación de 1898 a 1939, Leiden, Universitaire Pers Leiden, 1968.

SANTONJA, Gonzalo, "Introducción" a La guerra en Asturias (crónicas y romances), de César M. Arconada, Madrid, Editorial Ayuso, colección Biblioteca Silenciada-2, 1979, pp. 9-20.

TINIANOVA, Inna, "Evocación preliminar (A guisa de prólogo)" al tomo primero de las Obras escogidas de César M. Arconada, Moscú, Editorial Progreso, s. f. (¿1968?), pp. 3-15. 


\section{¡VIVE DOLORES!}

¿Qué dolor aquel día, camarada, qué sobresalto ahogaba los latidos, qué nube empañó las alegrías cuando dijeron:

Está nuestra Dolores en peligro!

Mientras de gozo aullaban los chacales, mientras los torvos buitres enemigos graznaban de alegría en los aleros de sus viejos palacios y castillos, a la orilla del Tajo, un ruiseñor expresaba su pena en dulces trinos y en Aragón bajaba la mirada por no llorar un viejo campesino, y en Bilbao un obrero junto al yunque, su angustia repicaba en el martillo, y en cualquier fría sierra de Castilla, en el regazo de la madre, un niño pedía que le hablasen de Dolores, porque ella era canción en sus oídos... ¿Qué dolor por los valles y los montes, qué dolor por collados y caminos, qué dolor por los viejos olivares, qué trémulo dolor llevan los ríos! ¡Qué dolor el de España, qué dolor el del pueblo, el de sus hijos cuando se supo:

la vida de Dolores, nuestra madre, está en peligro!

Y la pena de ayer es ya alegría, y luce el sol que nubes empañaran, y el corazón en nuestros pechos late con ritmo de gozosas esperanzas y el rumoroso viento mensajero, desparramando albricias, va hasta España para decir: 
¡Ya está su vida salva!

Agítense los carniceros buitres, comiencen a temblar los vendepatrias, vive Dolores, ¡y es más fuerte el pueblo!, vive Dolores, iy le crecen alas! Cuando como ave matinal y alegre esta noticia a las prisiones vaya, parecerá a los presos que una mano mella la reja atroz de sus ventanas; parecerá a los bravos guerrilleros que es más seguro el blanco de sus balas, y el minero, el obrero, el campesino sentirán su victoria más cercana; más odiados serán los enemigos y la lucha será más enconada; parecerá la Patria más querida, parecerá que España es más España... ¡Vive Dolores!

de manos de la muerte rescatada por la ciencia soviética, la ciencia que más la muerte niega y la vida ama!

¡Vive Dolores!

$$
\text { Y por esa vida, }
$$
que es el oro mejor que tiene España, por esa vida que han devuelto al pueblo, dando su corazón, el pueblo paga, y repiten sus labios fervorosos:

¡Una vez más, al gran Stalin, gracias!

(España Popular, México, 483, 30 de diciembre de 1949) 


\section{BARCELONA}

1939. “'MARCHAD, ROJOS DEL DIABLO!”

El viento, el sol, el mar, los pájaros, los niños, las silenciosas fábricas, los ríos, los góticos vitrales, la primavera en nido, mujeres apenadas, severos campesinos, las nieves pirenaicas, todo, como aterido, de coraje y de lágrimas, salía a los caminos a decirnos adiós, a darnos con su grito: "iMarchad, que si quedamos lucharemos lo mismo!", despedida de flores en un invierno frío.
Y sólo desde un coche, al margen del suplicio de un pueblo traicionado, vendido, tres militares yanquis, dos ingleses marinos, expertos enviados del oro y del cinismo, nos despiden con áspero puñal de regocijo: "¡Marchad, rojos del diablo, dejadnos ya tranquilos!"

¡Y no sabían que quedando España quedaba el pueblo invicto!

1949. CUENTAS GALANAS

$Y$ en Washington sus cuentas echan los mercaderes de la guerra y del crimen y del odio y de la horda: El pueblo es dócil. Franco nos da plenos poderes. Compramos un tesoro por cuatro perras gordas. Sobre este río un puente. Que vayan los expertos a ver los yacimientos de azogue, cobre, plomo. Que se explore el calado de los mejores puertos. Haremos en seguida más de treinta aeródromos. Minas, costas, mesetas, ciudades y poblados... Nos da Franco de España sus riquísimos dones. Y por si fuera poco, nos ofrece soldados 
seguros y aguerridos. Número: dos millones.

Igual que a la lechera, después del alboroto

de sus cuentas galanas, jay, su cantarillo roto!

1951. “FUERA DE ESPAÑA LOS YANQUIS!”

¡Y no sabían que quedando España quedaba el pueblo invicto!...

Y a la calle se ha echado en Barcelona, amenazante, unido, diciendo no a la guerra, restallando como una espada que se blande, el grito de ¡atrás los yanquis! ¡Mueran los verdugos! ¡Fuera especuladores y bandidos! ¿Queremos pan y paz y libertad! ¿Que tengan alegría nuestros hijos...!

Éste es el pueblo que lacayos y amos creían fácil de llevar, sumiso, a uncirle bajo el yugo de sus planes, a la muerte, a la guerra, al sacrificio. Éste es el pueblo que a la Unión Soviética jamás hará la guerra, como ha dicho Dolores. Este pueblo está latente, amenazante, vivo, con un ayer de heroicos combates, un hoy de rabia y de odios encendidos y un mañana que pugna por salir rompiendo las barreras con ahínco.

\section{ENVIO}

¡A los pueblos del mundo que por la paz combaten, Barcelona un saludo de hermana os envía, mas en ese saludo de lucha yo diría que el corazón unánime de toda España late! 


\section{ROMANCE DEL NIÑO BUENO Y EL CIVILÓN PATILARGO}

Por el camino venían un civilón patilargo $y$ otro de negro entrecejo, bisojo y mal encarado. $Y$ se encontraron a un niño que pasaba cabizbajo por delante los civiles como en presencia del diablo. - ¿Dónde camina el buen mozo?, dice el guardia patilargo con esa gran cabezota que parece la de un sabio. ¡Delante la Benemérita que la gorra esté en la mano!

El niño bueno se turba -iqué me va a pasar, Dios santo! porque en la gorra llevaba... -iEa, rapaz, vamos, vamos, quítate la gorra, y vea de qué pelaje es el asno! Se quita la gorra el niño, y por el suelo, rodando, salieron tres manzanitas como tres dorados pájaros. - ¡Hola!, ¿con que ésas tenemos?, mocoso y saltavallados, ahora mismo dinos dónde las manzanas has robado. $\mathrm{Y}$ tal tirón de la oreja le da, que la estira un palmo. El niño se echa a llorar: -Las cogí de aquel manzano... Se las llevaba a mi madre que está enferma hace ya un año. - ¿Y no sabes, piel de lobo, que las cosas tienen su amo? $\mathrm{Y}$ a su compañero dice:
-En menos que canta un gallo, vete al pueblo y tráeme aquí a la madre de este guapo. Con la boca, con los ojos, pide, suplica el muchacho: -iMi pobre madre está enferma, no puede ni dar un paso! - No te metas en mis fueros, mi mandado es mi mandado! Lo que importa es que me digas si te acuerdas de qué árbol las cogiste.

-Fue de aquél... -Una lección con mis manos voy a darte, por que seas en la vida un hombre honrado. $\mathrm{Y}$ diciendo estas palabras, El civilón patilargo Al niño bueno cogió fuertemente por los brazos y con soguilla cinchera lo amarró al tronco del árbol. ¿Qué fresco olor agridulce tenía el verde manzano! ¿Entre las ramas, los frutos eran para aquel muchacho como rosadas mejillas, como luceros dorados!... Por la carretera, a rastras, como un mísero trapo, trae el bisojo a la madre, sin fuerzas, el rostro pálido, el corazón dando brincos y la súplica en los labios. Y delante de la madre, el civilón patilargo, de los calzones del niño 
tira, de un tirón, abajo, y le pone en cueros vivos su cuerpo moreno y flaco. $\mathrm{Y}$ entonces los dos civiles, empuñando unos vergajos, comienzan a darle golpes como si fuera de trapo... Suplica la madre, clama, justicia piden sus labios, y las lágrimas del niño hacen en la tierra un charco. ¡Zas, zas!, resuenan los golpes. ¡Zas, zas!, como dos trallazos, y se agitan en protesta todas las ramas del árbol, y en el suelo, alrededor, hay un tapiz sonrosado de manzanas que da al niño el generoso manzano...

De pronto, cuatro hombres llegan: -¿Qué es esto? ¿Qué pasa? ¡Alto! ¡Manos arriba los guardias! ¡Salvajes, almas del diablo! Y desataron al niño y a la madre dieron ánimo.
Los sacaron al camino, los pusieron en un carro. Hicieron que los dos guardias recogieran del manzano todos los frutos caídos y los llevaran al carro. Y envueltos entre manzanas olorosas y entre ramos, la madre y el niño vuelven al pueblo, que está cercano. $Y$ al despedirse dice uno, dándole un beso al muchacho: - ¿Sabes quién somos nosotros? ¿Sabes quién hoy te ha salvado? ¡Los guerrilleros del monte! Y no está mal, por si acaso, que yo mi nombre te diga. Y exclamo: - ¡Ponte me llamo!

Y mientras por el camino el carro se iba alejando, con el rabillo del ojo miro el niño hacia el manzano, y vió entonces que los guardias en él estaban colgados

(Nuestro Tiempo, 2, 1 de octubre de 1951)

\section{ETERNAMENTE STALIN}

España tiene luto de crespones, sobra de cielo y amargor de hiel, sangran pena y dolor los corazones, los pueblos, ya por siempre, están sin Él.

Y las ondas del Tajo, y el arrullo del olivar sediento de más sombra, 
y la flor de Granada en su capullo

su nombre amado con tristeza hoy nombran.

Mas Él presente sigue en valles, angosturas, llanos de sol y pedregosas cumbres, y torna en viva luz las amarguras y hace leve la triste pesadumbre.

La fragua de su causa el temple acera, su nombre alas de audacia da a la gente, donde está su palabra y su bandera brota la lucha en caudalosa fuente.

Porque nos dio el aliento con que escribe la hazaña el héroe y el amor la vida, en el alma de España Stalin vive, nuestro pueblo español jamás le olvida.

Jamás ha de olvidar que cuando España, revuelta en sangre y en traición sañuda, ya era vendida inerme a gente extraña, Él nos tendió su generosa ayuda.

Tronchaba la metralla flor de niño, turbión era la vida, el canto lloro: tomó Él las flores bajo su cariño y de aquella semilla hizo un tesoro.

Y la madre española, madre de luchadores, hoy con su corazón en duelo preso, quisiera junto al féretro colocar unas flores $y$ en la frente estampar el postrer beso.

En la lucha del pueblo Stalin vive y en la lucha nos lleva a la victoria. ¿Quien abraza su causa eternidad recibe, porque eterna es su causa, eterna es su gloria!

(España Popular, México, 652, 27 de marzo de 1953) 


\section{Y LOS PUEBLOS DE ESPAÑA...}

Y los pueblos de España también lloran por el sol apagado, por el cielo de negro tul vestido, por la aurora hecha en la sangre espanto, frío y hielo.

Los hombres de Madrid y Guadarrama, los del Ebro y Teruel, los impulsivos mozos que combatían en la llama del Batallón Stalin entre olivos;

los que hoy su nombre escriben en los muros, los que dicen su nombre en las canciones, los que mueren al alba del futuro con su nombre en los bravos corazones;

esos sencillos hombres hoy sin gozo, el pobre campesino y el obrero, la cariñosa madre, el viejo, el mozo, la guardia armada de los guerrilleros,

bajan los ojos y repliegan alas, y con sus férreos puños de semilla, una lágrima enjugan que resbala cual perla de dolor por sus mejillas.

Y con el mismo puño húmedo en llanto, que el dolor aunque inmenso nunca abate, hoy por Stalin juran, sin quebranto, proseguir en el puesto de combate.

En montañas, ciudades, en aldeas con ellos sigue Stalin y su gloria; y su nombre, y su causa, y sus ideas los llevarán luchando a la victoria. 


\section{NUESTRA ESPAÑA}

Garrapatean plumas de ignominia. Un borrón en los negros papeles de la infamia.

Se ha hundido un estilete. Yo sé en qué corazón: en tu doliente corazón, España.

Sangre, dolor,

lágrimas.

-Míster.

-Señor.

Sus morros de tratantes asoman los bandidos, y de pudor se empañan los cristales.

El Pardo.

Luto de sombras en los barrancales.

$Y$ el viento en el alcor,

y la llorosa fuente soterraña, y las encinas, como secos puños, todo grita que ¡No!, que ${ }_{\mathrm{i} N O}$ !

¡Nuestra es España!

La venden y la compran,

la rasgan, la desgarran,

la hieren, la maltratan,

la hollan, la deshonran,

la escupen, la encenagan.

Hacen de ella ferial y granjería, trato y contrato, truhonada y trampa.

Hacen de ella sus risas, sus orgías, sus babas y sus roñas, su miseria y su oro, 
su apetito de buitres,

su avidez de chacales...

¡No! ¡No!

¡Ay! ¡No! ¡No!

¡Que es nuestra España!

¿Que es nuestra madre!

Pon tu pecho de dolmen castellano, mozo, a los invasores, quieren hacer de ti un soldado de la muerte, la infamia y los horrores.

Diles que eres la vida, que tu sangre no das por sus rapiñas.

¡Novia,

échales de la patria, que tu azahar te roban!

¡Mujer:

odio y no llanto!

Tocas de viuda te querrán poner, vístete de esperanzas y de cantos. Abuelo que en el llar hablas de Cuba, donde tu sangre diste por la patria, paz demandan tus nieves venerables, no ver de nuevo sus raposas zarpas.

Madre, un pájaro negro sobre la cuna vuela.

Madre,

¡alerta!

Su negra sombra te amenaza al hijo, diles que ¡NO!, que ¡No! ¡Canto de odio a la guerra!

Las insaciables zarpas de los yanquis nos roban, españoles, nuestra patria. ¡En pie los corazones valerosos, 


\section{que es nuestra España! \\ ¡A la lucha los hijos bien nacidos, que a nuestra dulce madre España ultrajan ${ }^{1}$ !}

(España Popular, México, 691, 25 de diciembre de 1953)

\section{El ALCALde de Móstoles}

Grave, solemne, divisando mundos, rostro de surcos y color de peña, con la vara de borlas en la mano y el corazón ardiente de pelea, salió al balcón consistorial y dijo ante España inclinando la cabeza: ¡Españoles, la patria está en peligro, alzaos a la lucha y defendedla!

Hoy otros invasores nos asaltan agitando las llamas de la guerra. ¡Buen alcalde de Móstoles, tu grito con nueva voz resuena en nuestra tierra!

(España Popular, México, 696, 29 de enero de 1954)

\section{ANTONIO MACHADO}

... Y llámase su señorío, pueblo, y el nombre de su hacienda, poesía, y se llama honradez el fuego que arde, y sencillez su casa, y eternidad el cielo que le envuelve, y el corazón que late dentro, España.

${ }^{1}$ El 26 de septiembre de 1953 se firmaron los acuerdos económico-militares con Estados Unidos. 
El jardín. Es invierno, y eternamente verdes están sus flores, olmos, limoneros. Así su voz, así sus versos.

Y llamó al aldabón.

Se abre la puerta.

Grave, sencillo, provincial, humano, labriego señorial, rector de olmedas, amo de las alondras matinales, señor de golondrinas y vencejos que traen con su danzar la primavera... -Don Antonio, ¡salud!

$$
\text { - ¡Ah, cuánto tiempo }
$$

sin verle! ¿Es que volvemos...?

Una luz de ansiedad su rostro baña. -No, don Antonio, que la misma sombra que cayó sobre España, envuelve a España. -Pasan los nublos.

-iPasan!

Los hitlers, mussolinis, ¿qué se hicieron?

¿Del verdor de sus eras qué ha quedado?

-Porque no por sabido es menos ciertodice el poeta: lo que nunca pasa, y siempre vive y vivirá es el pueblo. - ¿Sabe usted, don Antonio? ¡De "monte a mar" todo vendido, todo! - ¿Otra vez? Aunque siempre continuará el tramposo con sus trampas.

- Hoy el trato y maltrato es con los yanquis. -Jamás al amo rico le faltaron serviles servidores.

-Pero no es una hogaza lo vendido, el trato, don Antonio, es con España... -Sin duda alguna no hay mayor infame que el que a su madre lleva al mercado y la vende a los tratantes. 
Un silencio de gravedad nos cubre como el manto de un cielo cristalino cuando la aurora raya en los albores. Y prosigue con helada voz de padre de muchos versos y de muchos sueños:

-Mas todo no se vende por fortuna, ni se puede vender, ni se ha vendido nunca:

el ansia de vivir que hay en los pueblos, su coraje de lucha, sus anhelos de libertad y triunfo, de alegría... No se puede vender, usted lo sabe, el alma, la honradez, el arraigado amor que reza: ¡Patria!, la conciencia que clama por justicia, el dulce corazón que pide paz...

En fin, que no es posible felizmente vender al pueblo.

Y lo demás es triste, amigo mío, pero es accidental y pasajero.

¡El pueblo! ¡El pueblo! ¡He aquí la verdad, lo que es eterno!

... Y cuando salgo veo que el jardín del poeta está florido, iy es invierno!

Y si miro hacia España dolorida veo que sobre el hielo y la inclemencia vive la eterna primavera joven del pueblo y el poeta.

(España Popular, México, 701, 5 de marzo de 1954²)

${ }^{2}$ La revista introduce los versos de César $M$. Arconada con las siguientes palabras: "Publicamos a continuación algunos fragmentos de la poesía que ha escrito nuestro camarada el escritor César M. Arconada, en conmemoración del décimoquinto aniversario de la muerte del gran poeta en Collioure, pocos días después de haber cruzado la frontera". 
PASÓ EL TIEMPO...

Pasó el tiempo. El pueblo escribe nuevas hazañas valientes.

Manuela Sánchez vive en el pueblo eternamente.

Está forjada su fama

en el más recio metal

porque ella fue pueblo en llama, porque el pueblo es inmortal.

De su muerte, vida brota; no paz a su tumba, lucha pide su alma de patriota, su grandeza, que es mucha.

Y el pueblo español desvela, lucha, su filo no esconde, y al coraje de Manuela con su coraje responde. $Y$ así la lucha no amengua crepitando como un fuego, sin dar al franquismo tregua ni a sus amos el sosiego. $\mathrm{Y}$ en Barcelona, en las calles, -rebelde ardor, primaveraestaba Manuela Sánchez con su rebelde bandera. $Y$ en ciudad, pueblo, montaña, valle o llanura infinita, Manuela al pueblo acompaña y con él su boca grita: "¡Fuera los yanquis de España!" $Y$ yo sé lo que ella ansía, lo que millones de gente: 
¡Dolores volverá un día!

¡Viva España independiente!

\begin{abstract}
A Alberto,
EN Moscú,

1960

Que todos te atoleden, toledano, es justo, como al Tajo dar laureles, pues la pura verdad, no corre en vano la Sagra por tus venas y pinceles.

Pero tú no eres sólo olivo y llano, camino carretero y cascabeles, pan y cal de Castilla, y hortelano de cantos, huesos, cerros y alcaceles.

Venero de bondad, luz de alborada, justicia y rebeldía aquijotada, por los hombres amor, eso eres tú.

La España torrencial y luchadora, la España viva ayer y viva ahora, más un pico y veinte años en Moscú ${ }^{4}$.
\end{abstract}

\footnotetext{
${ }^{3}$ Poema manuscrito, escrito con tinta azul de pluma estilográfica, en un folio que acompaña al cuento mecanografiado "Fotografías de España" y que se conserva en la sección de Manuscritos (22541/2) de la Biblioteca Nacional de Madrid.

${ }^{4}$ Poema conservado entre los materiales del manuscrito 22606/28 de la Biblioteca Nacional de Madrid.
} 


\section{TODO ESTO DÍSELO TÚ}

Subo a un alto mirador... Quiero soñar lo remoto, y Pekín, alrededor, parece una flor de loto.

Corazón, pájaro en vuelo, vete con viento feliz, que el cuarenta paralelo va de Pekín a Madrid.

Este aire de vida nueva, este jardín que florece, esta fuerza que se eleva, este torrente que crece;

el hombre hecho dignidad, la fecunda tierra, un don, la justicia hecha verdad y el trabajo hecho canción;

el mozo y su fuerza plena, el niño y su cielo claro, la mujer ya sin cadenas y la vejez con amparo,

y estos afanes de acero, y este goce que ilumina de ver que ya el extranjero no roba la tierra china...

Avecica amada, escucha volando en el cielo azul: al pueblo español que lucha, todo esto díselo tús.

\footnotetext{
5 Poema mecanografiado en dos folios, que se conserva en la sección de Manuscritos (22540/3) de la Biblioteca Nacional de Madrid.
} 
GRIMAU, MUERTO INMORTAL...

Grimau, muerto inmortal, hijo de España, los cuervos decidieron de tu suerte: la muerte a sus graznidos acompaña, y cuanto tocan se trasforma en muerte.

Maldiciones os caen en aguaceros, os tenemos un odio sin confines. ¡Malditos seáis todos, carroñeros, arrasadores de albas y jardines!

Pero la vida es nuestra compañera, Grimau, tu compañera permanente; somos canción de siembra y primavera, somos un corazón siempre latente.

La ira del mundo a la venganza llama. Camarada Grimau, mi voz escucha: desde Moscú te mando un telegrama para decir que vives hecho lucha.

Un aire de clamor bulle sonoro, será multiplicada la proeza, que tú un nuevo valor has dado al oro del hombre comunista y su grandeza.

Con tu ejemplo la lucha irá adelante, será más productiva la labranza.

Cuando la dignidad se alza triunfante, crece el Hombre y aumenta la esperanza. 
Yo bien sé tu respuesta verdadera.

Camaradas: no quiero ya otra gloria:

itomad en vuestras manos mi bandera

y llevadla a una cumbre de victoria ${ }^{6}$ !

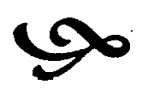

6 AA. VV., En memoria de Julián Grimau, Moscú, Editorial Progreso, s. f., pp. 5-6. Recuérdese que el 20 de abril de 1963 el comunista Julián Grimau García fue fusilado en Madrid por soldados del ejército franquista. 